\title{
Ants' Capability of Adding and Subtracting Odors
}

\author{
Marie-Claire Cammaerts ${ }^{1} \&$ Roger Cammaerts ${ }^{2}$ \\ ${ }^{1}$ Independent researcher, retired from the Biology of Organisms Department, University of Brussels, Belgium \\ ${ }^{2}$ Independent researcher, retired from the Natural and Agricultural Environmental Studies Department (DEMNA) \\ of the Walloon Region, Belgium \\ Correspondence: Marie-Claire Cammaerts, independent researcher, 27, Square du Castel Fleuri, 1170 Bruxelles, \\ Belgium. Tel: 32-2673-4969; E-mail: mccammaerts@gmail.com
}

Received: August 23, 2019

Accepted: September 21, 2019

Online Published: October 8, 2019

doi:10.5539/ijb.v12n1p1

URL: https://doi.org/10.5539/ijb.v12n1p1

\begin{abstract}
Summing and discriminating odors may be useful for animals in their daily life. The workers of the ant Myrmica sabuleti rely essentially on odors for navigating and have a rather poor visual perception. It was previously shown that they can add and subtract visual elements when the result of the operation has been concretely presented to them, i.e. they thus respond to an image which corresponds the best to that they have memorized. Here we examined if these ants can sum two odors and 'subtract' (discriminate) an odor from a mixture of two ones. They added two distinct odors only when these odors were presented side by side and perceived simultaneously, and not when they were located at some distance from one another and perceived consecutively. They discriminated one odor from a mixture when that odor was presented in association with a reward (the food). They subtracted one odor from a mixture when that specific odor was presented and perceived separately at a place not associated with a reward. Myrmica sabuleti workers could thus effectively add two odors and subtract one odor from a mixture, but only when the odor(s) to which they should respond was (were) associated with a reward. In the wild, such a behavior could help the ants to navigate.
\end{abstract}

Keywords: conditioning, extraction, Myrmica sabuleti, olfaction, sum

\section{Introduction}

Many animal species produce chemical signals for communicating with congeners as well as for marking their territory. An acute sense of smell often enables them to find food and navigate (Leroy, 1987). This is of course valid for insects, and especially for social insects. Several types of olfactory sensilla, essentially located on the antennae, collect odorous information which is transmitted to specific parts of the brain, what in turn induces adequate behavior (Renau, 2014).

In the wild, ants encounter plenty odors, issued from the members of their colony as well as from the environment. They have to use them either all together or separately. They must thus be able to add odors as well as to isolate one odor from others. We have shown that the workers of the ant Myrmica sabuleti Meinert 1861 can add and subtract visual elements, but only when the result of the addition and the subtraction is clearly perceptible (Cammaerts \& Cammaerts, 2019, c, d, e). Moreover, these workers have a concrete, basic notion of the zero (of nothing) based on visual as well as on olfactory elements (Cammaerts \& Cammaerts, 2019 a, b). We have also demonstrated that the workers of the ant $M$. sabuleti essentially use odors for navigating, and use visual cues only in the absence of odors (Cammaerts \& Rachidi, 2009). Consequently, we expect that M. sabuleti workers operate with olfactory cues at least as well as with visual ones, and may thus be able to add and subtract (isolate) odors, at least under some conditions. Here we aimed to experimentally check this hypothesis.

Bees have been studied as for their ability in adding and discriminating odors, essentially at a physiological and neuronal level, the functioning of their brain under olfactory stimulation having been investigated (Sandoz, 2011; Lachnit, Giurfa, \& Menzel, 2004). Classical conditioning experiments on restrained bees showed that they learn and recognize the odor of flowers thanks to key odorant (Reinhard, Sinclair, Srinivassan \& Claudianos, 2010). They can 'sum' and 'extract' odors. Other works more or less linked to the present one on ants, as well as extended information on the subject will be reported in the 'Discussion' section, after having related our methods and results, and having discussed them. 


\section{Material and Methods}

\subsection{Collection and Maintenance of Ants}

The experiments were conducted on four colonies of Myrmica sabuleti Meinert 1861, labeled A to D, maintained in the laboratory as usual. Each colony lived in two to three glass tubes half filled with water, a cotton plug separating the ants from the water. These nest tubes were set in a tray $(34 \mathrm{~cm} \times 23 \mathrm{~cm} \times 4 \mathrm{~cm})$ the borders of which having been covered with talc. This tray served as foraging area in which pieces of Tenebrio molitor larvae (Linnaeus, 1758) were deposited three times per week, and cotton plugged tubes filled with sugar water were permanently set. The collected colonies came from an abandoned quarry located in the Aise valley (Ardenne, Belgium); they contained a queen, brood and about 500 workers. In the laboratory, the ambient temperature was ca $20^{\circ} \mathrm{C}$, the humidity $80 \%$, the lighting 330 lux while working on ants, and the electromagnetism $2 \mu \mathrm{Wm}^{2}$. These environmental conditions were optimum for the species.

\subsection{Odors Presented to the Ants}

The odors used were those of lavender, thyme, orange and basilica. Were used the seeds and flowers of lavender, the leaves of thyme and basilica, and the outer part of an orange peel (= the flavedo). These pieces of plants were inserted into small glass tubes (diam: $0.5 \mathrm{~cm}$; length: $2 \mathrm{~cm}$ ) which were then slightly plugged with cotton. The odor of either one plant or two plants was so presented to the ants in a kind of diffuser, according to the experiment and the part of this experiment. Four experiments were made, each one including training and testing parts. For experiment I, made on colonies $\mathrm{A}$ and $\mathrm{B}$, the odor of lavender and that of thyme were used during training. The odors of lavender, of lavender + thyme, and of thyme were used during testing. For experiment II, made on colonies $\mathrm{C}$ and $\mathrm{D}$, the odors of orange and of orange + basilica were used during training. The odors of orange, of orange + basilica, and of basilica were used during testing. During experiment III, made on colonies A and B, the odor of orange and that of basilica were used during training. The odors of orange, of orange + basilica, and of basilica were used during testing. During experiment IV, made on colonies C and D, the odor of lavender and those of thyme + lavender were used during training. The odors of lavender, of lavender + thyme, and of thyme were used during testing. Schemas of the use of these odors are given in Figures 1 and 2; the experiment planning is summarized in Figure 3; and some photos of the experiments can be seen in Figures 4 to 7. Experiment III was conducted seven days after experiment I, and experiment IV was performed seven days after experiment II.

\subsection{Experimental Design and Protocol}

Looking to the figures and tables helps understanding the design and protocol described here below.

The ants were trained on their foraging area during three days. For experiment I, two odor diffusers one with lavender, the other with thyme, were both closely set near the ants' food, at one centimeter from one another (Figure 1, upper part; Figure 4, upper photos). For experiment II, a diffuser containing orange was set just aside the ants' food, and a diffuser containing orange and basilica was set far from the food (Figure 1, lower part; Figure 5 , upper photos). During experiment III, two diffusers one with orange the other with basilica were set on one and the other side of the food, i.e. not side by side, but at $5 \mathrm{~cm}$ from one another (Figure 2, upper part; Figure 6, upper photo). During experiment IV, two diffusers one with lavender the other with lavender + thyme were both set just aside of the food, at one centimeter from one another, and a diffuser with thyme was set far from the food (Figure 2: lower part; Figure 7, upper photo).

During training, each day, the ants being motionless or in movement all around the presented odors, whatever the location of these odors, were counted six times, at a time, over the day, and the mean value obtained for each colony was calculated (Table 1, second column). The overall mean for each experiment (that of the means obtained for each two used colonies) was also established and given in the text only.

The ants of each colony were tested twice (at days 2 and 3) in a separate tray $(30 \mathrm{~cm} \times 15 \mathrm{~cm} \mathrm{x} 4 \mathrm{~cm})$ the borders of which having been slightly covered with talc to prevent escaping, and into which were set the diffusers of the odors to which the ants were expected to react (Figures 1,2). For experiment I and IV, three diffusers were set, one with lavender, one with lavender + thyme, and one with thyme. For experiment II and III, three diffusers were also set, one with orange, one with orange + basilica, and one with basilica. To make a test, 25 ants of each colony were collected on the foraging area and at the nest entrance. They were transferred into a tray devoted to testing (Figures 4-7, lower part), and the ants present at a distance of $0-2 \mathrm{~cm}$ from each of the three presented diffusers were counted 20 times over 10 experimental minutes. The means of these counts were established (Table1, third column). The total numbers as well as the proportions of ants responding to each presented odor(s) are also given, but in the text only, not in a table. After each test, the ants were transferred again in their foraging area. 

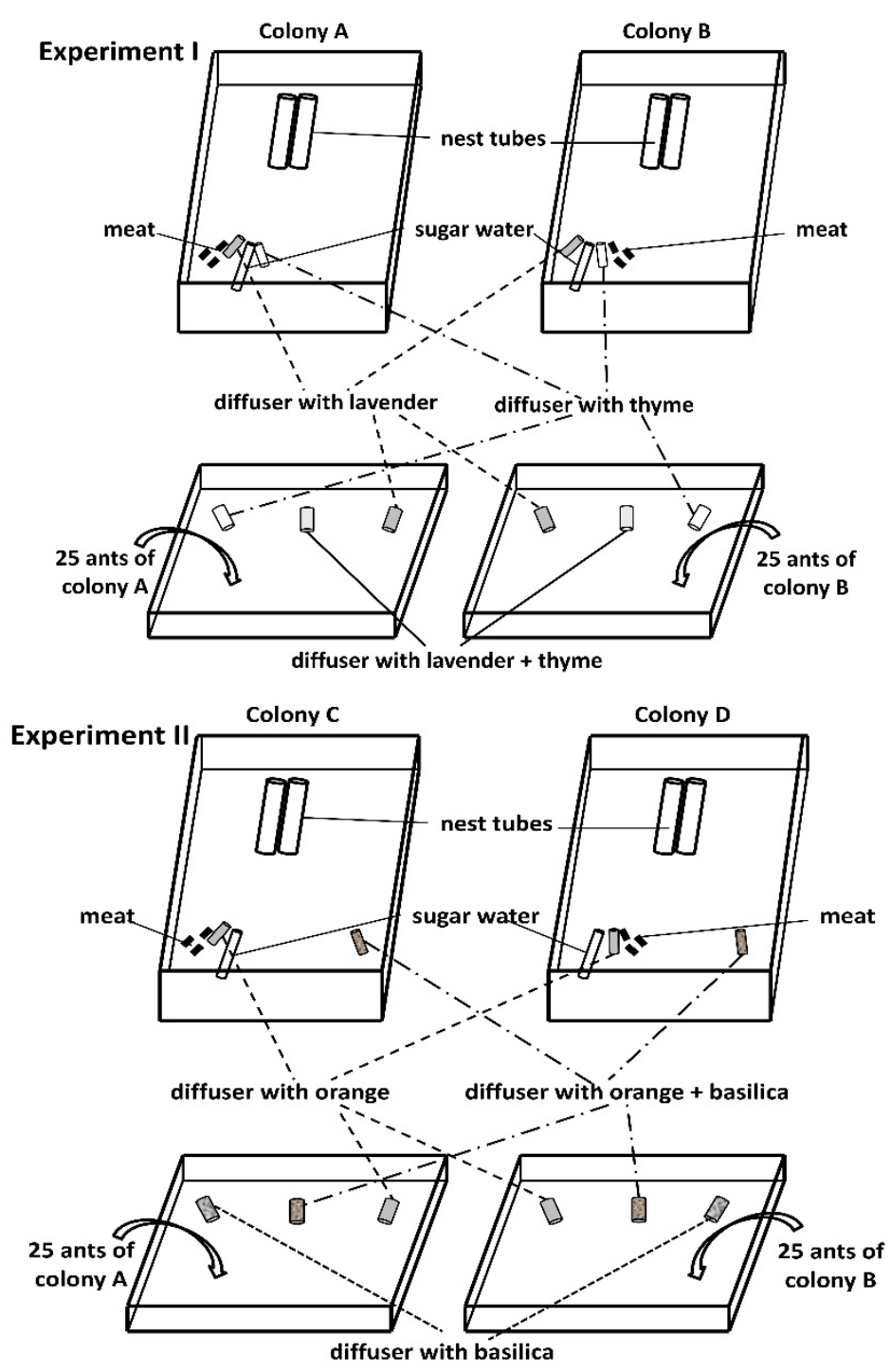

Figure 1. Schema of the experimental design used for experiments I (upper part) and II (lower part)

Experiment I was conducted for examining if ants could add two odors perceived simultaneously; experiment II was conducted for examining if they could extract an odor from a mixture when perceiving the result of the extraction. The ants were trained on their area (upper part of each schema), and tested in a separate tray (lower part of each schema). Details are given in the text, results in Table 1 (the two first parts), and some views of the experiments in Figures 4 and 5. 

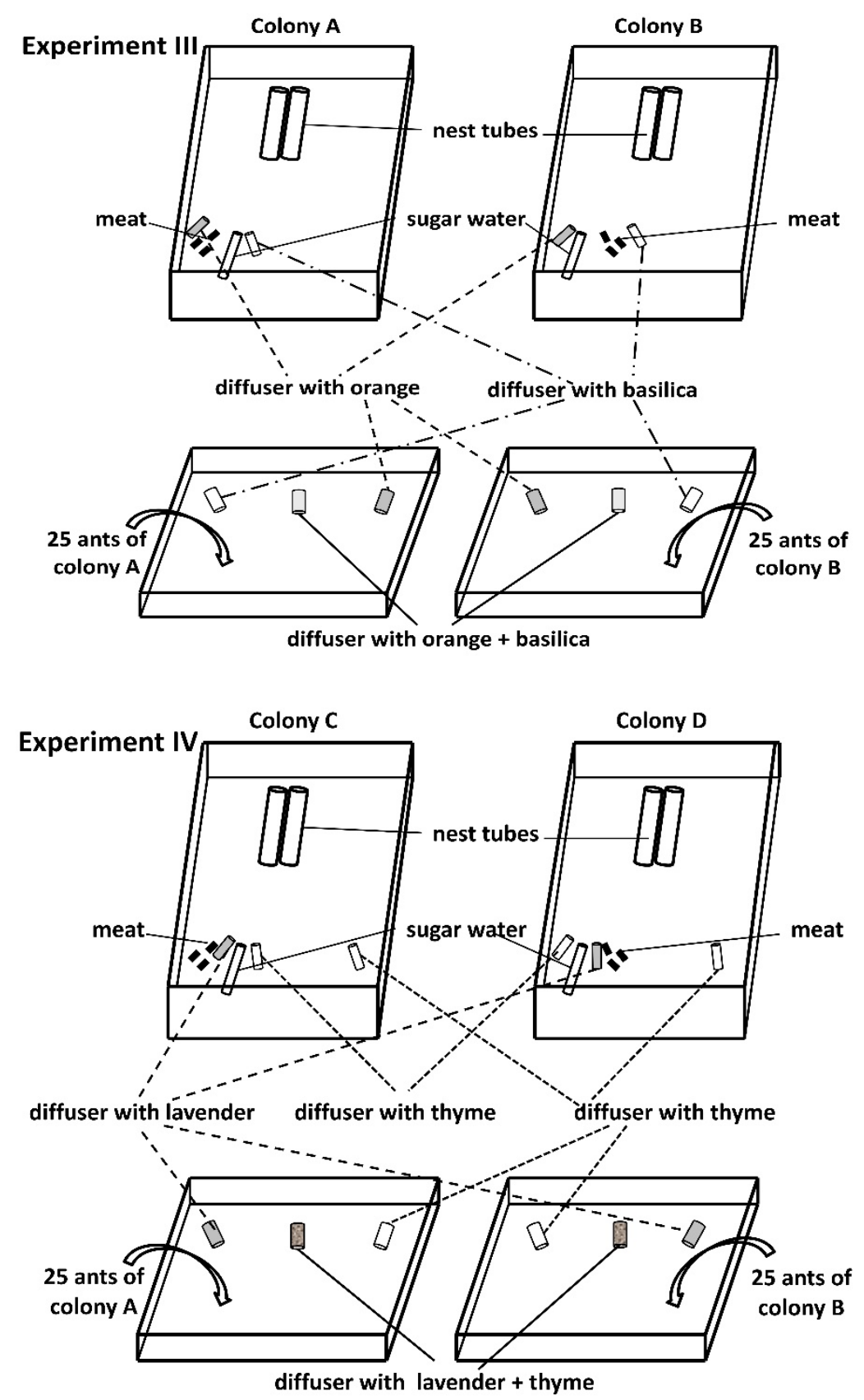

Figure 2. Schema of the experimental design used for experiment III (upper part) and IV (lower part).

Experiment III was performed for examining if ants could add two odors separately perceived; experiment IV was performed for examining if ants could extract an odor from a mixture when the expected result of the extraction (= the lavender odor) was not obviously presented, whilst the odor to subtract (= the thyme odor) was presented apart. The ants were trained on their area (upper part of each schema) and tested in separate trays (lower part of each schema). Details are given in the text, results are available in Table 1 (the two last parts), and some views of the experiments can be seen in Figures 6 and 7. 


\begin{tabular}{|l|c|c|c|}
\hline Experiments and what they investigated & Colonies & Training & Testing \\
\hline I odor addition, perceiving the result & A $\quad$ B & $\begin{array}{c}\text { lavender and thyme near food, } \\
\text { side by side }\end{array}$ & $\begin{array}{c}\text { lavender; thyme; } \\
\text { lavender + thyme }\end{array}$ \\
\hline II odor subtraction, perceiving the result & C $\quad$ D & $\begin{array}{c}\text { orange near food, } \\
\text { orange + basilica far from food }\end{array}$ & $\begin{array}{c}\text { orange; basilica; } \\
\text { orange + basilica }\end{array}$ \\
\hline III odor addition, not perceiving the result & A $\quad$ B & $\begin{array}{c}\text { orange and basilica near food, } \\
\text { not side by side }\end{array}$ & $\begin{array}{c}\text { orange; basilica; } \\
\text { orange + basilica }\end{array}$ \\
\hline IV odor subtraction, not perceiving the result & C $\quad$ D & $\begin{array}{c}\text { lavender and thyme near food, } \\
\text { side by side; thyme far from food }\end{array}$ & $\begin{array}{c}\text { lavender; thyme; } \\
\text { lavender + thyme }\end{array}$ \\
\hline
\end{tabular}

Figure 3. Experimental planning.

Four ant colonies were used to examine if these social insects could add and subtract odors when perceiving or not perceiving the result of the operation. In each case, two odors were used, but differed from one experiment to another in order to not use twice the same odors for the same colonies in a different experiment. The experimental design is shown in Figures 1 and 2; some photos of the experiments can be seen in Figures 4 to 7; numerical results are reported in Table 1, and details are given in the text.

\section{Training}

\section{Colony A}

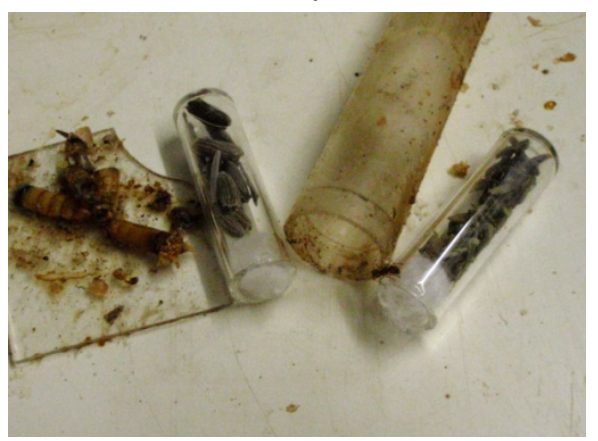

Colony A

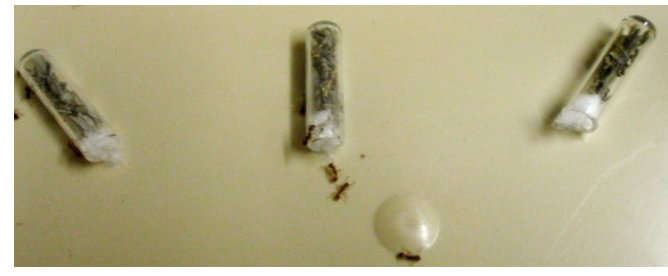

Colony B

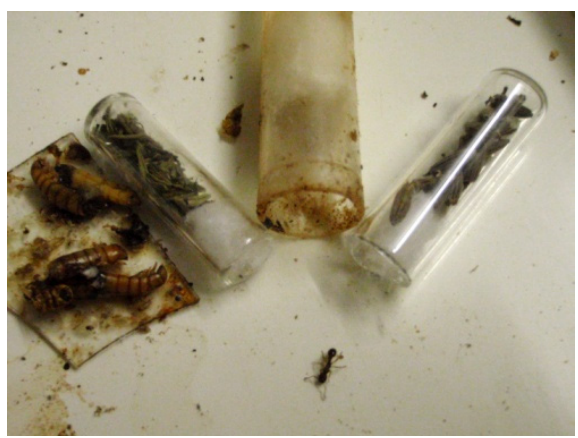

Testing

Colony B

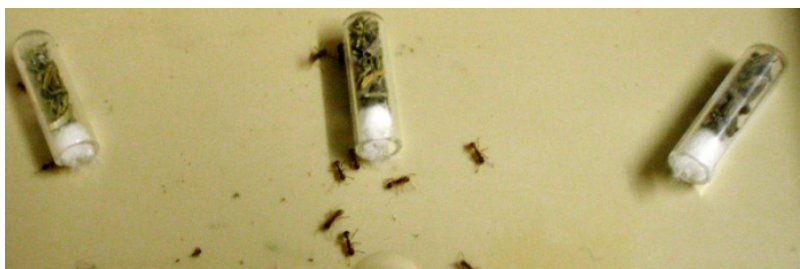

Figure 4. Some photos of experiment I

The ants were trained to the odors of lavender and of thyme set side by side close to their food (upper part of the figure). When tested in front of the odor of lavender, of thyme and of lavender + thyme, the ants went preferentially to the odor of lavender + thyme, having thus added (associated) the two odors. Numerical results are given in Table 1, first part; details and statistics are available in the text. 


\section{Training}

Colony C

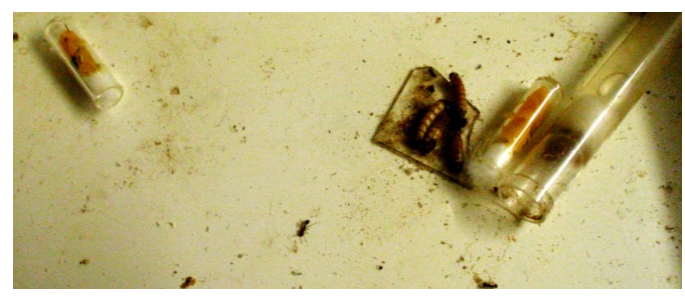

Colony D

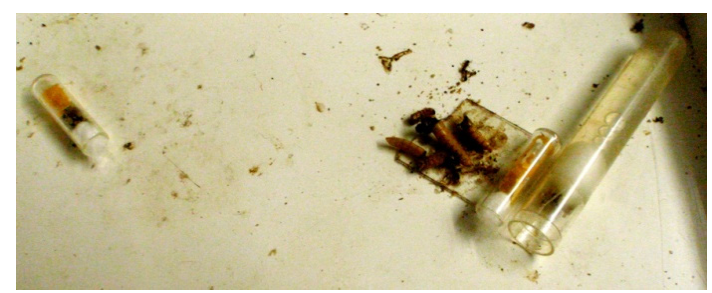

Testing

Colony C

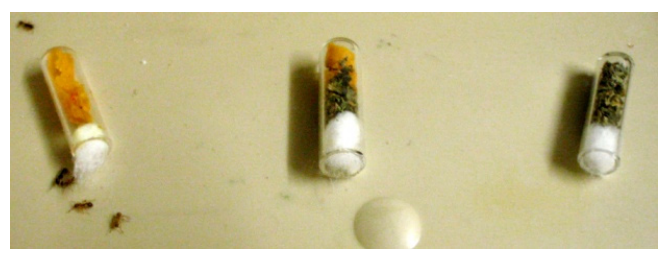

Colony D

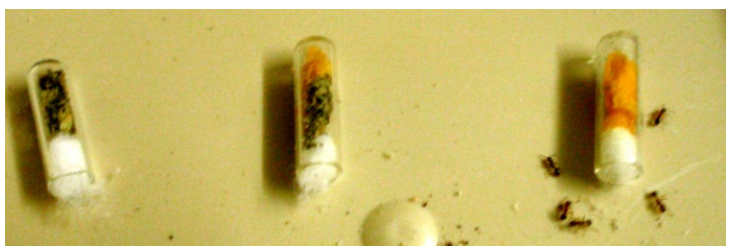

Figure 5. Some photos of experiment II

The ants were trained in the presence of the mixed odor of orange + basilica and of orange set near their food (upper part of the figure). When tested, they reacted essentially to the odor of only orange, being thus able to 'subtract' the odor of basilica. Numerical results are given in Table 1, second part; details and statistics can be found in the text.

\section{Training}

Colony A

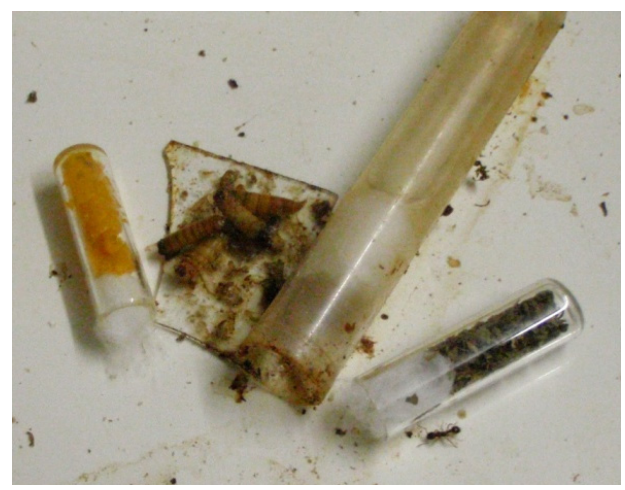

Colony A

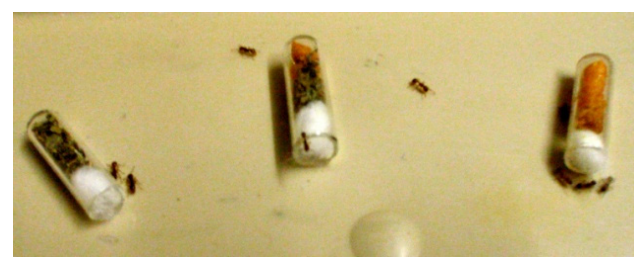

Colony B

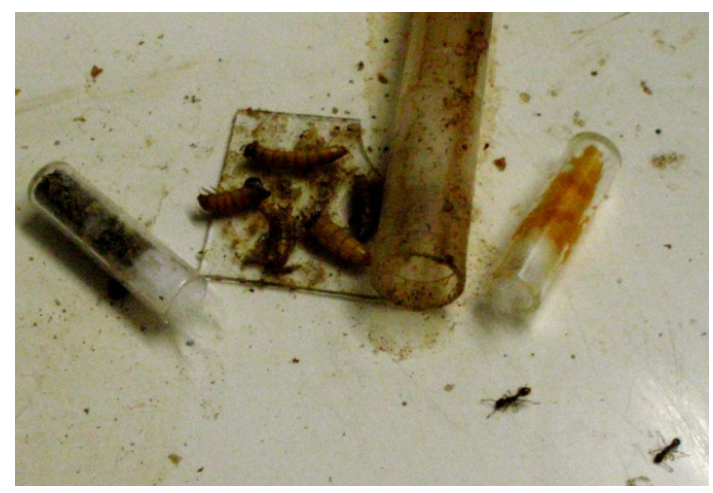

Testing

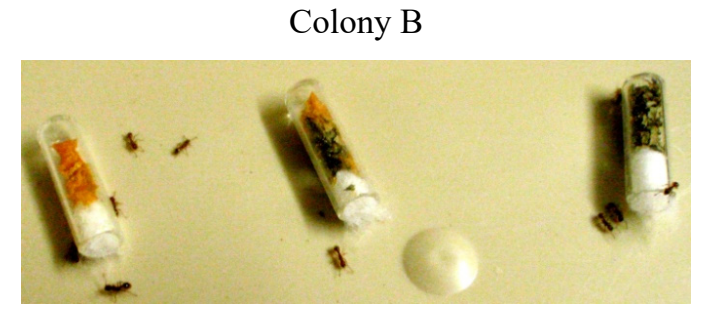

Figure 6. Some views of experiment III

The ants were trained to the odor of orange and of basilica set at a few centimeters apart, on each side of the food (upper part of the figure). They were tested in front of the odor of orange, of orange + basilica, and of basilica (lower part of the figure). The ants did not preferentially move to the odor of orange + basilica, but essentially to the odor of orange and to that of basilica. They thus did not add (associated) the two odors they perceived consecutively during training. Numerical results are given in Table 1, third part; details and statistics are available in the text. 
Experiment IV. Training

Colony C

Colony D
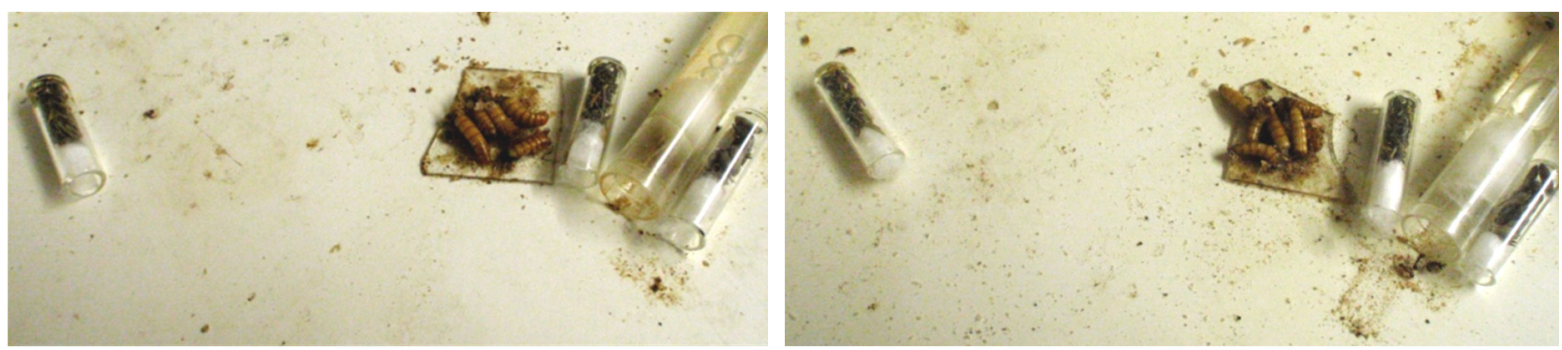

Experiment IV. Testing

Colony C

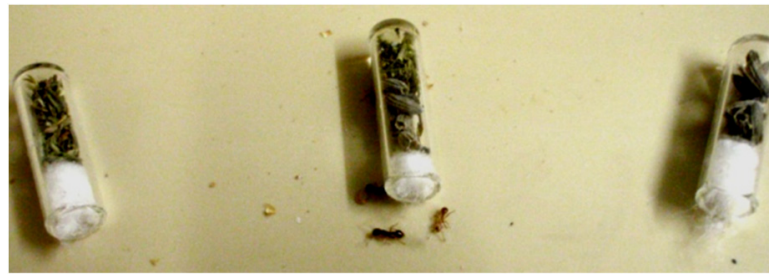

Checking experiment. Training

Colony C

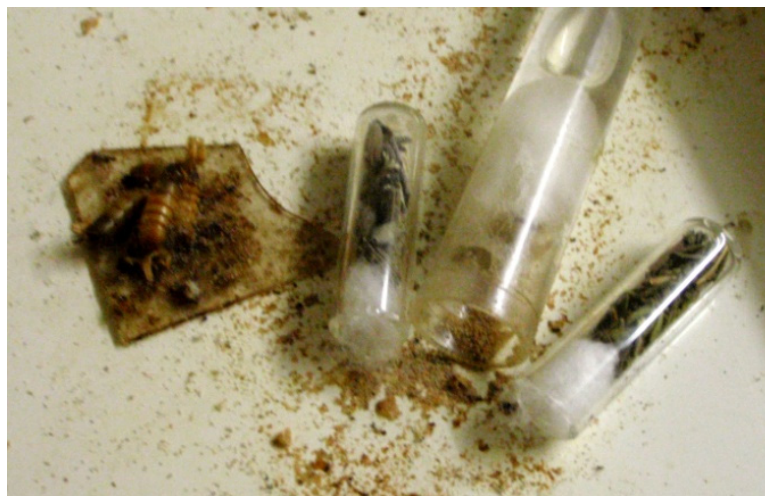

Colony D

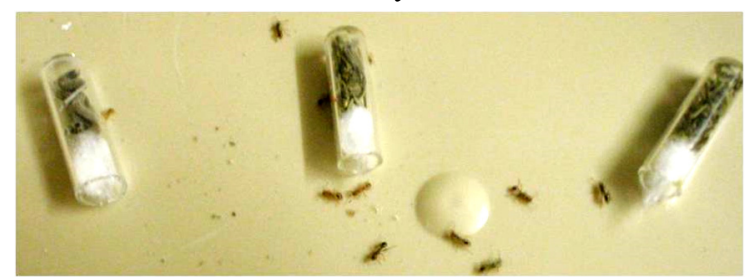

Colony D

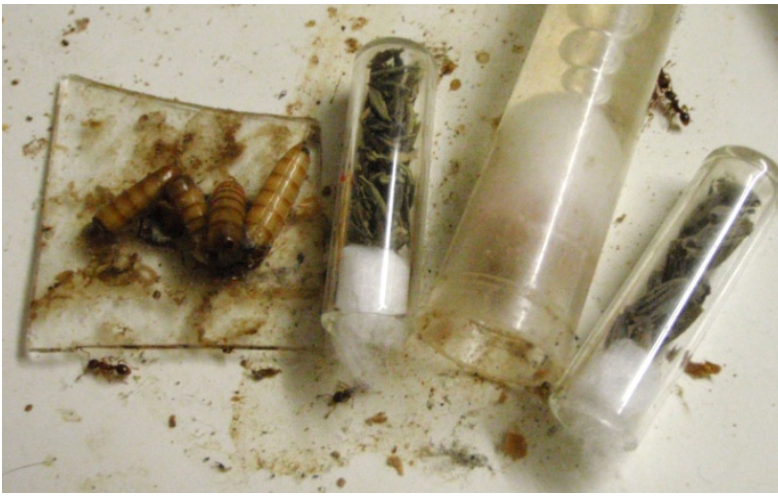

Checking experiment. Testing

Colony C

Colony D
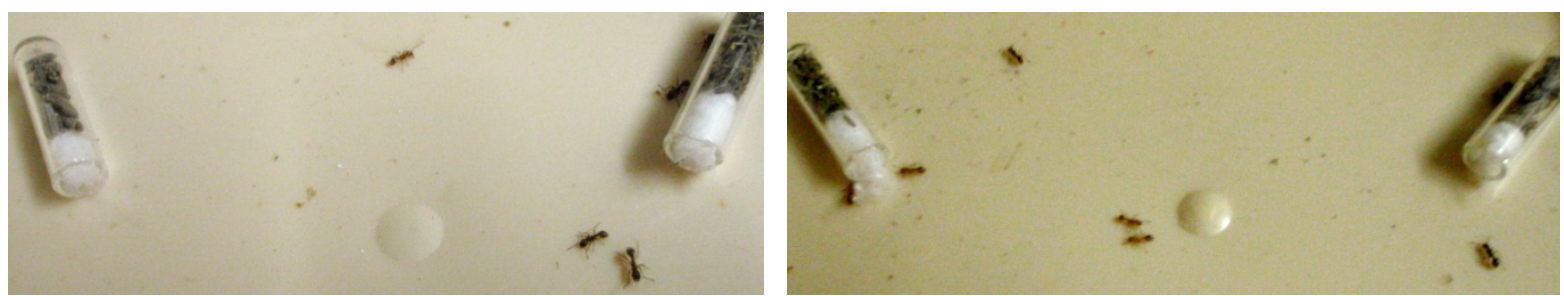

Figure 7. Some views of experiment IV.

The ants were trained to the odor of lavender and of thyme set side by side close to the food, and to the odor of thyme set far from the food (i.e. the odor to subtract) (upper part of the figure). They were tested in front of the odor of lavender, of lavender + thyme, and of thyme (lower part of the figure). The ants moved preferentially to the odor of lavender + thyme, but also somewhat to the odor of lavender. They thus only slightly suppressed the odor of thyme from the odors of lavender + thyme they have associated as in experiment I. A checking experiment (lower part of the figure) examined if such an ant' reaction may be due to their preference of the lavender odor. The checking experiment showed that the ants did not prefer the lavender odor to that of thyme. Numerical results are given in Table 1, fourth part; details and statistics can be found in the text. 
Table 1. Results of four experiments made to examine the ants' ability in adding and subtracting odors

\begin{tabular}{|c|c|c|c|c|c|}
\hline \multicolumn{2}{|c|}{ Experiment: } & \multirow{2}{*}{$\begin{array}{c}\text { Training: mean } \mathbf{n}^{\circ} \text { of ants near the odor } \\
\text { of lavender and of thyme }\end{array}$} & \multicolumn{3}{|c|}{ Testing: mean $n^{\circ}$ of ants approaching the odor of } \\
\hline days & colonies & & lavender & lavender + thyme & thyme \\
\hline \multirow[t]{2}{*}{ I: 1,2} & $\mathrm{~A}$ & 8.8 & 0.4 & 2.1 & 0.3 \\
\hline & B & 7.8 & 0.2 & 2.8 & 0.5 \\
\hline \multirow[t]{2}{*}{3} & A & 8.8 & 0.7 & 1.6 & 0.3 \\
\hline & $\mathrm{B}$ & 10.2 & 0.5 & 4.6 & 0.5 \\
\hline \multicolumn{2}{|c|}{ Experiment: } & Training: mean $n^{\circ}$ of ants near the odor & \multicolumn{3}{|c|}{ Testing: mean $\mathrm{n}^{\circ}$ of ants approaching the odor of } \\
\hline days & colonies & of orange and of orange + basilica & orange & orange + basilica & basilica \\
\hline \multirow[t]{2}{*}{ II: 1,2} & $\mathrm{C}$ & 8.9 & 2.5 & 0.5 & 0.1 \\
\hline & $\mathrm{D}$ & 9.3 & 5.2 & 1.3 & 0.3 \\
\hline \multirow[t]{2}{*}{3} & $\mathrm{C}$ & 8.3 & 2.4 & 0.8 & 0.3 \\
\hline & $\mathrm{D}$ & 11.5 & 4.3 & 1.5 & 0.1 \\
\hline \multicolumn{2}{|c|}{ Experiment: } & Training: mean $n^{\circ}$ of ants near the odor & \multicolumn{3}{|c|}{ Testing: mean $n^{\circ}$ of ants approaching the odor of } \\
\hline days & colonies & of orange and of basilica & orange & orange + basilica & basilica \\
\hline \multirow[t]{2}{*}{ III: 1,2} & $\mathrm{~A}$ & 8.8 & 4.2 & 0.9 & 1.6 \\
\hline & B & 8.9 & 2.6 & 1.2 & 2.9 \\
\hline \multirow[t]{2}{*}{3} & A & 8.7 & 2.5 & 0.5 & 1.5 \\
\hline & $\mathrm{B}$ & 9.5 & 2.2 & 0.8 & 2.9 \\
\hline \multicolumn{2}{|c|}{ Experiment: } & Training: mean $n^{\circ}$ of ants near the odor & \multicolumn{3}{|c|}{ Testing: mean $n^{\circ}$ of ants approaching the odor of } \\
\hline days & colonies & of lavender, of thyme, and of thyme & lavender & lavender + thyme & thyme \\
\hline \multirow[t]{2}{*}{ IV: 1,2} & $\mathrm{C}$ & 7.7 & 0.2 & 1.8 & 0.1 \\
\hline & $\mathrm{D}$ & 8.3 & 1.4 & 3.7 & 0.8 \\
\hline \multirow[t]{2}{*}{3} & $\mathrm{C}$ & 9.5 & 1.0 & 4.2 & 0.3 \\
\hline & $\mathrm{D}$ & 8.5 & 1.2 & 3.3 & 0.5 \\
\hline
\end{tabular}

The experiments aimed to examine successively, I: if ants could add two odors when clearly perceiving their sum; II: if ants could extract one odor from a mixture of two odors when clearly perceiving the result of the extraction, III: if ants could add two odors separately perceived; and IV: if ants could extract an odor from a mixture without perceiving the result of the extraction. The ants appeared to be able to make the addition and the extraction of an odor when they distinctly perceived the result of these operations, and to be unable to make the operations when their result was not clearly presented. Schemas of the experimental designs are given in Figures 1 and 2; the protocol is summarized in Figure 3, and photos are shown in Figures 4 to 7.

\subsection{Statistical Analysis}

The results relative to the ants' training required no statistical analysis.

Those concerning the ants' testing were analyzed as follows. The 20 numbers of ants obtained for each presented odor (at each testing day) were chronologically arranged and added by four, and the five sums so obtained (not written in the tables) for each odor were compared to one another using the non-parametric test of Wilcoxon (Siegel \& Castellan, 1989).

\section{Results}

\subsection{Experiment I}

Numerical results are given in Table 1, first part, and some photos are shown in Figure 4.

During their two first training days, the ants of colonies A and B were numerous enough near the two presented diffusers for learning, at the same time, the odor of lavender and that of thyme: meanly 8.3 ants were seen there at any time. When tested faced with the odor of lavender, of thyme and of lavender + thyme (these odors being set at a different place for each colony), the ants obviously went essentially to the diffuser emitting the mixed odor of lavender + thyme. In total, 12 ants, i.e. 9.7\%, were counted near the odor of lavender, 15 ants, i.e. $12.1 \%$, were counted near the odor of thyme, and 97 ants, i.e. $78.2 \%$, were counted near the odor of lavender + thyme. Summed by four over the experimental time, the numbers of ants approaching the odor of lavender equaled 4, 5, 1, 1, 1, those approaching the odor of thyme equaled $2,4,3,2,4$, and those approaching the odor of lavender + thyme equaled $22,20,21,17,17$. These three series of five values statistically differed $(\mathrm{N}=5, \mathrm{~T}=15, \mathrm{P}=0.031)$. The ants thus essentially reacted to the mixed odor of lavender + thyme when tested a first time. During one more training day, the ants of colonies A and B were again rather numerous near the two presented diffusers: meanly 9.5 ants were indeed seen at this place. Tested again, the ants of the two colonies again went more to the mixture 'odors of lavender and of thyme' than to each of the two odors separately presented. In total, 23 ants, i.e. 13\%, went to the odor of lavender, 124 ants, i.e. $70.1 \%$, went to the odor of lavender + thyme, and 30 ants, i.e. $16.9 \%$, went to the odor of thyme. Summed by four over the experimental time, the numbers of ants counted near the 
diffuser of the lavender odor equaled 7, 3, 5, 5, 3, those of ants counted near the diffuser of the lavender + thyme odor equaled 22, 31, 28, 20,23, and those of ants counted near the diffuser of the thyme odor equaled 9, 6, 4, 5, 6 . These three series of five values statistically differed $(\mathrm{N}=5, \mathrm{~T}=15, \mathrm{P}=0.031)$. The ants could thus add the odor of lavender and that of thyme perceived at the same time from two diffusers set very near from one another.

\subsection{Experiment II}

Numerical results are given in Table 1, second part, and some views of the experiment can be seen in Figure 5.

During their two first training days, the ants of colonies $C$ and $D$ were enough numerous around the two presented diffusers for perceiving and learning the odors emitted. Meanly 9.1 ants were counted, at any time, on this area. When tested after two days, the ants of the two colonies went preferentially to the diffuser of orange odor. In total, 153 ants, i.e. $79.3 \%$, were counted in front of the diffuser of orange odor, 34 ants, i.e. $17.6 \%$, were counted in front of the diffuser of the mixed orange + basilica odor, and 6 ants, i.e. $3.1 \%$, were counted in front of the diffuser of basilica odor. Summed by four over the experimental time, the numbers of ants seen near the source of orange odor equaled $36,30,31,31,25$, those seen near the source of orange + basilica odor equaled $11,6,8,4,5$, and those seen near the source of basilica odor equaled $0,4,1,0,1$. These three series of values statistically differed $(\mathrm{N}=5, \mathrm{~T}=15, \mathrm{P}=0.031)$. The ants have thus mostly reacted to the odor of orange only, and far less to the mixed odor of orange + basilica. During their third training day, the ants of colonies $\mathrm{C}$ and $\mathrm{D}$ were again rather numerous in the vicinity of the two presented diffusers, being meanly 9.9 in doing so at any time. When tested again, the ants of the two colonies once more preferentially went to the diffuser of orange odor. In total, 132 ants, i.e. $71.7 \%$, were counted aside the orange odor, 45 ants, i.e. $24.5 \%$, were counted aside the mixed orange + basilica odor, and 7 ants, i.e. $3.8 \%$, were counted aside the basilica odor. Summed by four over the experimental time, the numbers of ants seen in front of the diffuser of orange odor equaled 29, 31, 24, 24, 24, those in front of the diffuser of orange + basilica odor equaled $11,10,11,5,8$, and those in front of the diffuser of basilica odor equaled $0,0,2$, 2,3 . These three series of five values statistically differed $(\mathrm{N}=5, \mathrm{~T}=15, \mathrm{P}=0.031)$. Consequently, the ants strongly reacted to the odor of orange only, and far less to that odor mixed with that of basilica. The ants could perceive the difference between 'orange odor' and 'orange + basilica odor', and could mentally make abstraction of (= subtract) the odor of basilica and react to the orange odor only.

\subsection{Experiment III}

Numerical results are given in Table 1, third part, and some views of the experiment can be seen in Figure 6 .

When trained to the odors of orange and of basilica set at 5 centimeters from one another, thus not side by side but one odor at one side of the food and the other odor at the other side of the food, the ants of colonies A and B were at any time numerous enough in the vicinity of these two odors for perceiving them consecutively, one odor then the other. When tested after two training days faced with the odor of orange, of basilica and of orange + basilica, the ants of the two colonies did not go preferentially to the diffuser of the orange + basilica odor, but went essentially to the diffuser of the orange odor and to the diffuser of the basilica odor. In total, 135 ants, i.e. 50.8\%, were counted near the orange odor, 41 ants, i.e. $15.4 \%$, were counted near the orange + basilica odor, and 90 ants, i.e. $33.8 \%$, were counted near the basilica odor. Summed by four over the experimental time, the numbers of ants seen near the orange odor equaled $42,40,23,22,8$, those seen near the orange + basilica odor equaled $17,15,6$, 3,0 , and those seen near the basilica odor equaled $29,24,12,11,14$. The five values relative to the odor of orange and to that of basilica did not statistically differ $(\mathrm{N}=5, \mathrm{~T}=-12,+3, \mathrm{P}=0.156)$, but each of these two series of values statistically differed from the five values relative to the orange + basilica odor $(\mathrm{N}=5, \mathrm{~T}=15, \mathrm{P}=0.031)$. The ants reacted thus separately to the odor of orange and to that of basilica, and did not add them. During their third training day, the ants of colonies A and B were again rather numerous at any time near the two presented odors, being meanly 9.1 on such places. When tested again, the ants of the two colonies again approached more the diffuser of orange odor and that of basilica odor than that of orange + basilica odor. In total, 92 ants, 45.5\%, were counted in front of the diffuser of orange odor, 25 ants, i.e. $12.4 \%$, in front of the diffuser of orange + basilica odor, and 85 ants, i.e. $42.1 \%$ in front of the diffuser of basilica odor. Summed by four over the experimental time, the numbers of ants seen near the orange odor equaled $27,18,14,15,18$, the numbers of those seen near the orange + basilica odor equaled 7, 7, 2, 4, 5, and of those seen near the basilica odor equaled 26, 23, 12, 13, 11. The first and the third of these three series of five values did not statistically differ $(\mathrm{N}=5, \mathrm{~T}=+4,-11, \mathrm{P}=0.219)$, but each of these two series statistically differed from the second series of five values $(\mathrm{N}=5, \mathrm{~T}=15, \mathrm{P}=0.031)$. Consequently, the ants did not add the two odors when these odors were presented a few centimeters apart from one another and reacted to each of these two separated odors. 


\subsection{Experiment IV}

Numerical results are given in Table 1, fourth part, and some photos of the experiment are presented in Figure 7.

When trained to the odor of lavender and of thyme set side by side near their food (and thus adding them, see experiment I) and at the same time to the thyme odor set far from the food, the ants of colonies $\mathrm{C}$ and $\mathrm{D}$ were numerous enough all around these odors for perceiving, localizing and memorizing them. They were indeed meanly 8 in doing so at any time. When tested after two training days in front of the lavender odor, that of lavender + thyme, and that of thyme, the ants of the two colonies approached essentially the diffuser of the lavender + thyme odor, and far less the two other diffusers. In total, 31 ants, i.e. 19.6\%, were counted near the lavender odor, 109 ants, i.e. $69.0 \%$, were counted near the lavender + thyme odor, and 18 ants, i.e. $11.4 \%$, were counted near the thyme odor. Summed by four over the experimental time, the numbers of ants seen in front of the lavender odor equaled $8,5,6,5,7$, those seen in front of the lavender + thyme odor equaled $27,24,20,16,22$, and those seen in front of the thyme odor equaled $1,1,4,8,4$. The series of five numbers of ants relative to the lavender + thyme odor statistically differed from the two other series $(\mathrm{N}=5, \mathrm{~T}=15, \mathrm{P}=0.031)$. As for the latter two series of five values, even if the values relative to the lavender odor were somewhat larger than those relative to the thyme odor, the two series of values did not statistically differ $(\mathrm{N}=5, \mathrm{~T}=+2.5,-12.5, \mathrm{P}=0.125)$. Consequently, the ants added the odor of lavender and that of thyme (as in experiment I) and statistically did not suppress (subtract) the thyme odor from the odor of lavender + thyme. During their third day of training, the ants of colonies $\mathrm{C}$ and $\mathrm{D}$ were again numerous in the vicinity of the three presented diffusers for learning the odors and their localization. They were indeed meanly 9 in doing so at any time. When tested again on day 3, the ants of the two colonies again approached more the diffuser of the lavender + thyme than the two other diffusers. In total, 44 ants, i.e. $20.6 \%$, were counted near the diffuser of lavender odor, 156 ants, i.e. $72.9 \%$, were counted near the diffuser of lavender + thyme odor, and 14 ants, i.e. $6.5 \%$, were counted near the diffuser of thyme odor. Summed by four over the experimental time, the numbers of ants seen near the lavender odor equaled 17, 10,8, 4, 5, those of ants seen near the lavender + thyme odor equaled $33,37,31,25,29$, and those seen near the thyme odor equaled $2,3,1,0,8$. The series of five values corresponding to the odor of lavender + thyme statistically differed from the two other series $(\mathrm{N}=5, \mathrm{~T}=$ $15, \mathrm{P}=0.031)$. These two other series differed at the limit of statistical significance $(\mathrm{N}=5, \mathrm{~T}=+1,-14, \mathrm{P}=0.063)$, what could convey some tendency in subtracting the odor of thyme. It could thus be concluded that the ants trained to the odor of lavender plus that of thyme set aside the food, and to the odor of thyme set far from the food, mostly reacted to the odor of lavender + thyme they mentally added. Nevertheless, they somewhat reacted to the odor of lavender alone after a total of three training days. It cannot be ruled out that they showed some tendency in subtracting the odor of thyme from the mixture lavender + thyme, but it remained to check if ants were not attracted by the odor of lavender. A checking experiment has thus been done. Trained to lavender odor and thyme odor set side by side and tested in front of only the lavender odor and the thyme odor presented separately (and no longer in front of the mixed lavender + thyme odor), the ants of colonies $\mathrm{C}$ and $\mathrm{D}$ had some tendency in moving preferentially to the diffuser of thyme odor. In total, 47 ants, i.e. $38.5 \%$, were counted near the lavender odor and 75 ants, i.e. $61.5 \%$ were counted near the thyme odor. Summed by four over the experimental time, the numbers of ants seen in the vicinity of the lavender odor equaled 10,13,11, 7, 6, and those of ants seen in the vicinity of the thyme odor equaled 26, 22, 13, 6, 8. These two series of five values differed at the limit of significance $(\mathrm{N}=$ $5, \mathrm{~T}=-1,+14, \mathrm{P}=0.063)$. Thus, the ants slightly preferred the thyme odor. After their third training day, the tested ants again reacted slightly more to the thyme odor than to the lavender odor. In total, 59 ants, i.e. $39.1 \%$, were counted near the lavender odor, and 92 ants, i.e. $60.9 \%$, were counted near the thyme odor. Summed by four over the experimental time, the numbers of ants which approached the lavender odor equaled 11, 12, 9, 13, 14, and those which approached the thyme odor equaled $27,15,16,17,17$. This time, these two series of five values statistically differed $(\mathrm{N}=5, \mathrm{~T}=15, \mathrm{P}=0.031)$. Consequently, during the experiment $\mathrm{IV}$, it can be admitted that the ants did not go more towards the lavender odor because they preferred that odor, but because they somewhat subtracted the thyme odor from the mixed lavender + thyme odor. Let us add that in the course of other experiments using pieces of thyme placed on the ants' foraging area, the ants transported these pieces of thyme to their nest entrance, presenting thus some attraction for this aromatic plant.

\section{Discussion, Conclusion}

Aiming to go on with our investigation on the ants' numerosity abilities, we here examined if these social insects could add an odor to another (= sum two odors) and subtract one odor from a mixture of two odors (= mentally extract one odor from a mixture). We experimentally found that the workers of the ant $M$. sabuleti added two odors presented at the same time side by side and thus perceived simultaneously, but did not add two odors presented at the same time at about five centimeters from one another and thus perceived only consecutively. We also found that these ants could extract one odor from a mixture of two odors when the result (= the odor to extract) was 
clearly perceptible, and could only hardly extract an odor from such a mixture when the result (= the odor to extract, to 'keep') was not obviously perceived, and when the odor to subtract was not perceived at the same time. However, the ants seemed to become able to do so in the course of training, and a checking observation allowed excluding a possible ants' preference for the odor 'to keep', i.e. to 'extract'. These findings are in agreement with those previously obtained about the ants' ability in adding and subtracting a visual element: they could do so only when the result of the operation (the sum or the difference) was visually clearly perceptible (Cammaerts \& Cammaerts, $2019 \mathrm{c}, \mathrm{d}, \mathrm{e})$. The workers of the ant $M$. sabuleti essentially use odors for navigating, and use visual cues only in the absence of odor (Cammaerts \& Rachidi, 2009). They are more expert with odors than with visual elements, having effectively small eyes and a rather large subtended angle of vision (Cammaerts, 2004). The fact that these workers could better subtract an odor than a visual element is thus logical. In the wild, summing two odors present side by side and thus perceived at the same time, as well as mentally extracting one odor present at a particular place among other odors, may be useful for finding and remembering the way. Not adding two odors present at some distance from one another, as well as not extracting an odor from a mixture when only this mixture has to be memorized (when none of its odors is present at a to be avoided place), is also what is required for being able to correctly navigate.

Let us state that the intensity of the odor (the amount of vegetal pieces set in the diffuser) did not influence the ants' response. Indeed, trained to a diffuser fully filled with lavender and to a diffuser fully filled with basilica, the two being set side by side, the tested ants went more to a diffuser half filled with lavender and half filled with basilica (Experiment I and IV).

Bees (Apis mellifera) have been experimented as for their potential ability in adding and subtracting visual elements. After having been trained through conditioning to, according to their color, add or subtract one element from a small number of elements, the bees were shown to be able to simultaneously add and subtract one element, although virtually not present, from a number of one to five elements, even if some of them were absent during training (Howard, Avarguès-Weber, Garcia, Greentree, \& Dyer, 2019). Bees are also very sensitive to odors. Their ability in discriminating odors and mixtures of odors is known since a long time and is spectacular (Pham-Delègue, Masson, Etiévant, \& Azar, 1986; Pham-Delègue, Etiévant, Guichard, \& Masson, 1989; Pham-Delègue, Bailez, Blight, Masson, Picard-Nizou, \& Wadhams, 1993). Even if being probably less performing than bees, some ant species may however proceed like them.

In insects, the odors and their mixture are perceived by the antennae the information of which is treated in particular parts of the brain, the later in turn inducing reactions, behaviors, choices or emissions of substances. This process has largely been examined on bees (e.g. Akers \& Getz, 1993; Lachnit et al., 2004). It should be of interest to make similar neurophysiological investigations on the ants' brain under olfactory stimulation. This is not impossible since simple basic studies of this kind have already been done (Lopez-Riquelme, Hermandez-Falcon, \& Ramon, 2009).

Ants, bees, social hymenoptera and even insects are only some of numerous animal species for which odors play important roles in their daily life (Wilson \& Stevenson, 2006). Odors actually have plenty of physiological and ethological functions (Leroy, 1987), but we have to limit our survey of literature to the subject of the present paper, i.e. the abilities in adding and subtracting odors. Being able to make these operations is useful in numerous circumstances, and is detained by animals pertaining to nearly all taxa (Leroy, 1987). The neuronal mechanisms operating for perceiving chemical compounds seem to be similar for different animal taxa (Hildebrand \& Shepherd, 1997). Such a similarity may be the case for adding odors and for integrating the components of an odor mixture (Duchamp-Viret, Duchamp, \& Chaput, 2003). This is also valid for humans: their olfactory functioning is physiologically similar to that of animals (Walker \& Jennings, 1991). It is well known by anyone that dogs are expert in discriminating one kind of odor among plenty ones and dogs are indeed used by humans on the basis of this efficient ability. Scientific information can be found in Miklosi (2015). Rats can also discriminate between two odors (subtract one odor and respond to the other one) using probably more than a single olfactory property of each odor (Laing, Murray, King, \& Cairneross, 1974). Concerning the addition of odors and the olfactory perception of mixtures of volatile compounds, Thomas-Danguin et al. (2014) report in their review all what was up to then known in humans and animals. They state that the addition of odors, the perception of mixtures of odors, and the underlying mechanisms are widespread, including in humans.

Odors are thus of importance for all animals, and being able to add and subtract odors may be very useful in their daily life. Ants, as eusocial insects, and specially the species $M$. sabuleti which relies essentially on odors for navigating, should thus be able to operate with odors. Here, we showed, at a behavioral level, that the ant $M$. sabuleti can add and subtract an odor when the result is obviously perceptible and could be useful, but not when the two odors are located far from one another (addition) or when mentally extracting an odor is not useful. Such 
results are in agreement with previous ones relative to the addition and the subtraction of visual elements, though the studied ant species is naturally more effective with odors than with visual elements. Bees have also been shown to have this ability, and this has been neurologically examined (Akers \& Getz, 1993, references in the introduction section). We suggest that a similar investigation should be conducted on ants' olfactory abilities.

\section{Conflict of interest}

We affirm having no conflict of interest as for the subject here presented.

\section{References}

Akers, R.P. \& Getz, W.M. (1993). Response of olfactory receptor neurons in honeybees to odorants and their binary mixtures. Journal of Comparative Physiology, A, 173: 169-185. https://doi.org/10.1007/BF00192976

Cammaerts, M.-C. \& Cammaerts, R. (2019a). Ants are at the first stage of the notion of zero. International Journal of Biology, 11(1), 54-65. https://doi.org/10.5539/ijb.v11n1p54

Cammaerts, M.-C. \& Cammaerts, R. (2019b). Ants' notion of zero through the perception of the absence of an odor. International Journal of Biology, 11(2), 1-12. https://doi.org/10.5539/ijb.v11n2px

Cammaerts, M.-C. \& Cammaerts, R. (2019c). Ants' capability of adding numbers of identical elements. International Journal of Biology, 11(3), 25-36. https://doi.org/10.1007/BF00192976

Cammaerts, M.-C. \& Cammaerts, R. (2019d). Ants fail to add numbers of same elements seen consecutively. International Journal of Biology, 11(3), 37-48. https://doi.org/10.1007/BF00192976

Cammaerts, M.-C. \& Cammaerts, R. (2019e). Subtraction-like effect in an ant faced with numbers of elements which includes a crossed one. International Journal of Biology, 11(4), 51-66. https://doi.org/10.1007/ BF00192976

Cammaerts, M.-C. \& Rachidi, Z. (2009). Olfactory conditioning and use of visual and odorous elements for movement in the ant Myrmica sabuleti (Hymenoptera, Formicidae). Myrmecological News, 12, 117-127. https://myrmecologicalnews.org/.../index.php?...117-127...

Cammaerts, M.-C. (2004). Some characteristics of the visual perception of the ant Myrmica sabuleti. Physiological Entomology, 29: 472-482. https://doi.org/10.1007/BF00192976

Duchamp-Viret, P., Duchamp, A. \& Chaput, M.A. (2003). Single olfactory sensory neurons simultaneously integrate the components of an odour mixture. European Journal of Neurosciences, 18, 2690-2696. https://doi.org/10.1007/BF00192976

Hildebrand, J.G. \& Shepherd, G.M. (1997). Mechanisms of olfactory discrimination: converging evidence for common principles across phyla. Annual Review of Neurosciences, 20, 595-631. https://doi.org/10.1146/ annurev.neuro.20.1.595

Howard, S.R., Avarguès-Weber, A., Garcia, J.E., Greentree, A.D. \& Dyer, A.G. (2019). Numerical cognition in honeybees enables addition and subtraction. Cognitive Neuroscience, 5, 1-6. https://doi.org/10.1126/ sciadv.aav0961

Lachnit, H., Giurfa, M. \& Menzel, R. (2004). Odor processing in honey bees: is the whole equal to, more than, or different from the sum of its parts? Advances in the Study of Behavior, 34, 241-264. https://doi.org/10. 1126/sciadv.aav0961

Laing, D.G., Murray, K.E., King, M.G., Cairneross, K.D. (1974). A study of olfactory discrimination in the rat with the aid of a new odor delivery technique. Chemical Senses, 1(2), 197-212. https://doi.org/10.1093/ chemse/1.2.197

Leroy, Y. (1987). L'univers odorant de l'animal. Société nouvelle des éditions Boubée, Paris. Retrieved from https://www.abebooks.fr/rechercher-livre/titre/1\%27univers-odorant-de-1\%27animal/

Lopez-Riquelme, G.O., Hermandez-Falcon, J. \& Ramon, F. (2009). Correlations between antennae (electroantennogram) and brain (ERPs) response during odour stimulation in ants. Program N0 68.20/V4. Neuroscience Meeting Planner. Chicago, IL: Society for Neuroscience. Online. Retrieved from https://www.researchgate.net/...Antennae_Electroantennogram...Br...

Miklosi, A. (2015). Dog Behaviour, Evolution, and Cognition. Oxford University Press. https://doi.org/10.1126/ sciadv.aav0961 
Pham-Delègue, M.H., Bailez, O., Blight, M.M., Masson, C., Picard-Nizou, A.L. \& Wadhams, L.J. (1993). Behavioral discrimination of oilseed rape volatiles by the honeybee Apis mellifera L. Chemical Senses, 18, 483-494. https://doi.org/10.1126/sciadv.aav0961

Pham-Delègue, M.H., Etiévant, P., Guichard, E., \& Masson, C. (1989). Sunflower volatiles involved in honeybee discrimination among genotypes and flowering stages. Journal of Chemical Ecology, 15, 329-343. https://doi.org/10.1126/sciadv.aav0961

Pham-Delègue, M.H., Masson, C., Etiévant, P. \& Azar, M. (1986). Selective olfactory choices of the honeybee among sunflower aromas: a study by combined olfactory conditioning and chemical analysis. Journal of Chemical Ecology, 12, 781-793. https://doi.org/10.1126/sciadv.aav0961

Reinhard, J., Sinclair, M. Srinivassan, M.V. \& Claudianos, C. (2010). Honeybees learn odour mixtures via a selection of key odorants. PLoSONE, 5, e9110. https://doi.org/10.1371/journal.pone.0009110

Renau, M. (2014). Pheromones and general odor perception in insects. Chap 2 of Neurobiology of Chemical Communication. Ed: Mucignat-Caretta C., Boca Raton (FL), CRC Press / Taylor \& Francis. https://doi.org/10.1371/journal.pone.0009110

Sandoz, JC. (2011). Behavioral and neurophysiological study of olfactory perception and learning in honeybees. Frontiers in Systems Neuroscience, 5(98), 1-20. https://doi.org/10.3389/fnsys.2011.00098

Siegel, S., \& Castellan, N.J. (1989). Nonparametric statistics for the behavioural sciences. Singapore: McGrawHill Book Company. https://www.amazon.com/Sidney-Siegel...Statistics.../B008WDIR6

Thomas-Danguin, T., Sinding, C., Romagny, S., El Mountassir, F., Atanasova, B., Le Berre, E. ... \& Coureaud, G. (2014). The perception of odor objects in everyday life: a review on the processing of odor mixtures. Frontiers in Psychology, 5(article ${ }^{\circ}$ 504), 1-18. https://doi.org/10.3389/fpsyg.2014.00504

Walker, J.C. \& Jennings, R.A. (1991). Comparison of Odor Perception in Humans and Animals. In: The Human Sense of Smell, pp 261-280. Springer. https://doi.org/10.1007/978-3-642-76223-9_13

Wilson, D.A. \& Stevenson, R.J. (2006). Learning to Smell: Olfactory Perception from Neurobiology to Behavior. Baltimore, Maryland. Johns Hopkins University Press, 309pp. Retrieved from https://researchers.mq. edu.au/.../learning-to-smell-olfactory-percep...

\section{Copyrights}

Copyright for this article is retained by the author(s), with first publication rights granted to the journal.

This is an open-access article distributed under the terms and conditions of the Creative Commons Attribution license (http://creativecommons.org/licenses/by/4.0/). 